\title{
Los nuevos actores de la información televisiva: ciudadanos y periodistas como protagonistas del infoentretenimiento
}

\author{
Sara ORTELls BADENES \\ sortells@uji.es \\ Universitat Jaume I de Castelló
}

Recibido: 4 de abril de 2014

Aceptado: 20 de noviembre de 2014

\begin{abstract}
Resumen
Los programas de infoentretenimiento, cada vez con mayor presencia en las televisiones públicas y privadas, comparten una serie de características que los diferencian del resto de contenidos del periodismo audiovisual. Este artículo analiza específicamente el papel que adopta la audiencia, y el propio periodista, en la elaboración de este tipo de espacios. Para ello, se ha utilizado una metodología de análisis de contenido cuantitativo que se ha aplicado sobre una muestra formada por 4 programas de infoentretenimiento: Madrid directo (Telemadrid), Andalucía directo (Canal Sur), España directo (TVE) y En connexió (Canal 9). Los principales resultados determinan que en los espacios de infoentretenimiento los ciudadanos anónimos pasan a ser las fuentes informativas predominantes, y que el periodista se convierte en parte activa de la noticia, adquiriendo el rol de coprotagonista.
\end{abstract}

Palabras clave: Infoentretenimiento, Audiencia, Periodista, Información televisiva.

\section{The New Actors of Television News: Citizens and Journalists as Infotainment Main Protagonists}

\begin{abstract}
Infotainment programmes, which are increasing their presence on public and private TV Stations, share an amount of features that make them different from the rest of the audiovisual journalism contents. This paper is focused specifically on the role adopted by the audience, and by the journalists, in the production of this type of programmes. We have used a methodology based on quantitative analyses of content that has been applied to a sample of 4 infotainment programmes: Madrid directo (Telemadrid), Andalucia directo (Canal Sur), España directo (TVE) y En connexió (Canal 9). Main results determine that in the infotainment shows anonymous citizens turn to be the main sources, and journalists become an active part of the news, playing a co-star role.
\end{abstract}

Keywords: Infotainment, Audience, Journalist, Television News.

\section{Referencia normalizada}

ORTELLS BADENES, Sara (2015): "Los nuevos actores de la información televisiva: ciudadanos y periodistas como protagonistas del infoentretenimiento". Estudios sobre el Mensaje Periodístico. Vol. 21, Núm. 1 (enero-junio), págs.: 491-508. Madrid, Servicio de Publicaciones de la Universidad Complutense.

Sumario: 1. Introducción. 2. Las características del infoentretenimiento. 3. El papel de la audiencia como fuente informativa en el periodismo televisivo tradicional. 4. La presencia del periodista en la información televisiva tradicional. 5. Metodología. 6. Resultados. El papel de los ciudadanos en los programas de infoentretenimiento; 6.1. Las fuentes informativas en los programas de infoentretenimiento; 6.2. Características de las declaraciones de las fuentes informativas. 7. Resultados. El papel del periodista en los programas de infoentretenimiento; 7.1. La presencia del periodista en los programas del infoentretenimiento; 7.2. El periodista como único protagonista de la noticia; 7.3. La relación entre el presentador y el periodista en las conexiones en directo. 8. Conclusiones. 9. Referencias bibliográficas. 


\section{Introducción}

Conseguir audiencia a cualquier precio. Esta podría ser la máxima que siguen los medios televisivos que, debido a la lógica comercial que rige su funcionamiento, necesitan diseñar nuevas estrategias para captar a los espectadores, y mantener las inversiones publicitarias. La hibridación de géneros periodísticos se perfila como una opción muy utilizada para cumplir esta finalidad. En las últimas décadas la fusión de los géneros informativo y de entretenimiento, originando el llamado infoentretenimiento, se ha consolidado como un factor clave para configurar las parrillas de programación de televisiones públicas y privadas.

Desde su aparición a finales de la década de los 80 este fenómeno ha protagonizado numerosas investigaciones. El objetivo principal de estos estudios se ha centrado principalmente en el análisis de las consecuencias que se derivan de la implantación del infoentretenimiento en el tratamiento de la información política (Blumer, 1999; Sparks, 2000; Thussu, 2007; Casero-Ripollés, 2011; Nguyen, 2012), puesto que su aplicación se asocia a un aumento del peso de las noticias de temática blanda (Brants 1998 y 2008; Bird, 2000; Missika, 2006). Asimismo, también se han realizado diferentes trabajos en los que se ha valorado el impacto que este nuevo tipo de mensajes tienen sobre la audiencia (Van Zoonen, 1998; Aldridge 2001; Baum, 2002; Prior, 2003; Dader, 2007; Rowe, 2010).

Este artículo analiza el infoentretenimiento desde una perspectiva novedosa. El fenómeno híbrido se concibe como un formato de programa independiente y específico del espacio televisivo, que se ha implantado de manera visible en las parrillas de programación de cadenas públicas y privadas. Cuando hablamos aquí de infoentretenimiento no nos referimos a la presencia de ciertos rasgos característicos en programas informativos tradicionales como los noticiarios (Ortells-Badenes, 2009), sino a nuevos formatos que combinan la información y el entretenimiento en un único espacio. Actualmente, existe una nueva generación de programas de esta índole. Encontramos ejemplos en casi todas las cadenas televisivas: Madrid directo en Telemadrid, $\mathrm{Co}$ mando Actualidad en Televisión Española, o Callejeros viajeros en Cuatro. Televisiones autonómicas y nacionales incorporan a su oferta este tipo de contenidos. Por tanto, en este artículo se ofrece un enfoque original que se aleja del tratamiento recibido en las investigaciones previas, en las que el infoentretenimiento se ha abordado como un conjunto de características aisladas que afectan a la elaboración de piezas informativas concretas, como las noticias sobre política. Además, específicamente, este trabajo estudia rasgos concretos, hasta ahora no explorados, relacionados con el cambio en la concepción tradicional de los papeles que deben de desempeñar ciudadanos y periodistas en el proceso de elaboración de la información. Esta investigación se articula en base a dos hipótesis centrales:

- Hipótesis 1. Los ciudadanos anónimos se convierten en las fuentes informativas predominantes que se utilizan en los programas de infoentretenimiento para elaborar las noticias.

- Hipótesis 2. El periodista se convierte en parte activa de la noticia, adquiriendo el rol de coprotagonista, en los programas de infoentretenimiento. 
Los resultados extraídos de este estudio permiten establecer las principales características que definen el nuevo rol de los profesionales del periodismo y los espectadores en la producción de los programas de infoentretenimiento.

\section{Las características del infoentretenimiento}

En las últimas décadas del siglo XX empieza a percibirse una clara tendencia de los medios hacia la espectacularización de la información (Cebrián Herreros, 2003) que deriva en un aumento de la emisión de noticias en las que se potencia el lado humano de los hechos para atraer la atención de la audiencia (Thomas, 1990; Brants, 1998; Lozano, 2005; Dader, 2007; McManus, 2009; Rowe, 2010). Si hasta hace dos décadas el entretenimiento y los programas informativos eran géneros completamente diferenciados (Cebrián Herrero, 2004), la llegada del infoentretenimiento permite aunar ambos en un único espacio.

Nos referimos a un fenómeno que se ha consolidado y que afecta al conjunto de los contenidos televisivos. No obstante, no podemos hablar de un proceso de implantación acabado porque está en constante evolución. De hecho, la definición del infoentretenimiento está sujeta a pequeños matices que se modifican a medida que se introducen nuevos cambios para seguir sorprendiendo a la audiencia. El primer acercamiento al concepto realizado por Krüger (1988) ha ido ampliándose con el paso de los años con numerosas aportaciones que han tratado en profundidad el fenómeno híbrido.

La definición más completa, redactada por Brants (2008), la ofrece la Encyclopedia of Political Communication que habla del infoentretenimiento como una tendencia en la que priman los contenidos blandos. Este autor lo describe como un fenómeno que se caracteriza por personalizar las noticias, y adoptar enfoques basados en el interés humano para construir aquellas piezas informativas relacionadas con las temáticas duras, como la política. Brants sugiere la utilización del término para designar además diferentes tipos de programas como los talk show, en los que se mezcla la seriedad con la diversión, y las opiniones con los sentimientos privados. En definitiva, aquellos espacios en los que lo popular pasa a formar parte del terreno informativo.

Retomando la propuesta de Brants añadiremos que el infoentretenimiento aparece como resultado de la mercantilización de la información, que provoca que los medios televisivos busquen nuevas fórmulas para presentar la actualidad con la finalidad de desmarcarse de la competencia para captar a la audiencia, y de esa manera, atraer las inversiones publicitarias. Como consecuencia directa aumenta el peso de la visión suave de todo tipo de noticias, incluso de aquellas de temática dura (Reinemann et al. 2012). Lo cotidiano, lo popular y lo trivial se convierten en el eje informativo. Se apuesta por mostrar el lado más humano de los hechos, personalizando la información para despertar cualquier tipo de emoción en la audiencia y conseguir que se implique en la realidad que le rodea.

Actualmente no deberíamos hablar del infoentretenimiento como una mera tendencia hacia lo espectacular o lo humano, porque, aunque en constante cambio, ya se ha consolidado como fenómeno autónomo. Posee sus propias características formales y estilísticas para presentar la actualidad de una agenda mediática que también ha te- 
nido que adaptarse a la nueva demanda informativa. Su manera de plasmar la información a partir de una serie de pautas técnicas muy marcadas, como los movimientos continuos de cámara, la grabación al hombro o el ritmo de montaje dinámico, ha generado un estilo propio que ha dado pie a la creación de programas realizados íntegramente a partir de ese conjunto de reglas. Espacios en los que la información y el entretenimiento se fusionan hasta tal punto que resulta imposible delimitar las fronteras entre un género y otro, creando nuevos espacios televisivos con identidad propia.

A diferencia de la propuesta de Brants, al hablar de programas específicos de infoentretenimiento excluimos los talk shows puesto que concebimos como formato puro aquellos programas de entretenimiento que se estructuran a partir de una base informativa. Actualmente en las parrillas de programación de las televisiones nacionales encontramos diferentes formatos de espacios de infoentretenimiento. Aquellos que se estructuran a partir de varias noticias con temáticas diferentes que se realizan en directo, como sería el caso de Madrid directo (Telemadrid), o los programas de reportajes monotemáticos enlatados como Callejeros (Cuatro) o Salvados (La Sexta).

\section{El papel de la audiencia como fuente informativa en el periodismo televisivo tradicional}

Independientemente de los incipientes cambios que está experimentando el periodismo audiovisual, las fuentes informativas siguen siendo una pieza clave para elaborar las noticias (Dimitrova y Strömbäck, 2009). El acceso a las fuentes es indispensable para producir cualquier tipo de información, ofrecer distintos puntos de vista, contrastar y dar credibilidad a lo que se está contando (Gans, 1980; Manning, 2001; Oliva y Sitjà, 2007). No obstante, el nuevo panorama comunicativo impuesto por el infoentretenimiento también modifica la relevancia de los protagonistas. Actualmente, en este tipo de programas las fuentes oficiales, antes predominantes, comparten ahora escenario, cada vez con más frecuencia, con ciudadanos anónimos. La voz de los espectadores cobra relevancia. La audiencia deja de ser pasiva para convertirse en parte activa de la construcción del mensaje periodístico (Currah, 2009, García Avilés, 2011).

Si hasta hace unos años los periodistas buscaban temas a partir de las fuentes que conforman su agenda, de la observación de la competencia, o de las convocatorias de prensa, ahora, los propios ciudadanos se convierten en un recurso para encontrar nuevos hechos noticiosos. Se trata de una generación de espectadores que aparte de ofrecer declaraciones, puede aportar además material audiovisual grabado por ellos mismos (Currah, 2009). El contenido generado por el usuario (CGU) para documentar su día a día o cuestiones puntuales de interés (Paulussen y D’heer, 2013) cobra relevancia hasta convertirse, en muchos casos, en una fuente de información primordial para los medios de comunicación (García de Torres, 2010). La Primavera Árabe, el movimiento 15-M, o más recientemente, la Primavera Valenciana, se han documentado minuto a minuto en las redes sociales por los propios protagonistas. Información e imágenes que los medios televisivos han utilizado para elaborar sus noticias.

En el caso de la televisión, la participación ciudadana se acentúa con la expansión del infoentretenimiento. Aparte de encarnar un papel primordial en este tipo de espa- 
cios televisivos, el espectador desempeña además un rol activo en la construcción de la agenda mediática de las redacciones de este tipo de espacios. Los ciudadanos no se limitan a tomar parte en la producción de piezas informativas con sus declaraciones, sino que además, sugieren temáticas a los editores de los programas. La audiencia utiliza las redes sociales, el correo electrónico y el teléfono para ofrecer sus propias propuestas temáticas, propiciando así una relación directa con el programa, potenciando las máximas de cercanía y proximidad que caracterizan este tipo de espacios. Del volumen de sugerencias que los espectadores envían cada día, aproximadamente el $20 \%$ acaban convirtiéndose en noticia en estos espacios (Ortells-Badenes, 2012). Por tanto, cabe destacar que el ciudadano adopta un doble papel en los programas de infoentretenimiento: se convierte en elemento central y protagonista de la noticia, por un lado, $\mathrm{y}$ en suministrador de propuestas de nuevas informaciones por otro, haciendo que la cotidianeidad y la anécdota se configuren como hechos noticiables.

$\mathrm{El}$ infoentretenimiento supone por tanto una predilección por el periodismo de testimonio en el que la revelación de lo privado centra gran parte de las nuevas noticias (Harrington, 2008). La intimidad de personas completamente anónimas adquiere relevancia informativa (Turner, 2006) otorgando al ciudadano la posibilidad de compartir su cotidianeidad con el resto de espectadores de manera voluntaria y gratuita. La audiencia adopta un nuevo rol que le confiere el papel de fuente informativa de primer orden, convirtiendo a la televisión en "el reino de los cualquiera" (Prado et al., 1999:201). Ese rasgo se ha extendido al resto de la producción de la información periodística (Monclús y Vicente-Mariño, 2010), constatando que el fenómeno híbrido es capaz de influir y transformar la práctica del periodismo introduciendo nuevos parámetros.

\section{La presencia del periodista en la información televisiva tradicional}

Si analizamos la literatura que establece las bases del periodismo audiovisual clásico, la aparición en pantalla de los redactores siempre debería estar bien justificada (Oliva y Sitjà, 2007; Gordillo, 2009). No obstante, a pesar de que el peso de los informadores en la elaboración de los programas informativos televisivos sigue siendo escasa (Pestano Rodríguez, 2008), esta tendencia está cambiando, y cada vez resulta más común que los redactores salgan en pantalla a diario sin apenas justificación.

Los periodistas aparecen cada vez más en los noticiarios televisivos a través de las entradillas insertadas en los vídeos o las conexiones en directo, que han aumentado en los últimos años. Se pierde así la función de estos elementos informativos, centrada en ofrecer datos actualizados y de última hora, que queda reducida a una exhibición de la capacidad técnica del medio y de la personalidad del propio redactor en panta1la. Se está forjando una nueva manera de elaborar noticias que deja entrever la influencia de los programas de infoentretenimiento en los que estos recursos se han convertido en un rasgo identificativo como veremos a continuación.

\section{Metodología}

El estudio del papel que desempeñan los ciudadanos y los periodistas en la elaboración de los contenidos de los programas de infoentretenimiento es un tema original en 
este campo. Para llevar a cabo esta investigación se ha utilizado un método de análisis de contenido cuantitativo en el que la unidad de estudio es la noticia.

La muestra seleccionada está formada por 4 espacios de infoentretenimiento vespertino del panorama televisivo español: Madrid directo (Telemadrid), elegido por ser el primer formato de esta índole a nivel nacional, Andalucía directo (Canal Sur), por ser el segundo programa más veterano, España directo (Televisión Española), porque durante 5 años se convirtió en el único programa de referencia de cobertura nacional, y su esencia se conserva en el programa + Gente que lo ha substituido desde septiembre de 2011, y En connexió (Canal 9), como ejemplo de programa autonómico de lengua no castellana, emitido en la Comunidad Valenciana. En total se han analizado 684 piezas informativas, emitidas entre mayo y junio de 2010: 130 de Madrid directo, 205 de Andalucía directo, 236 de España directo y 114 de En connexió.

Se ha diseñado un modelo de análisis dividido en dos bloques diferenciados para determinar, por una parte, el índice de participación de la audiencia, y por otra, el papel que se le otorga al periodista en la elaboración de los contenidos de este tipo de programas.

Para analizar el papel de los ciudadanos en la producción del mensaje informativo en los programas de infoentretenimiento se han tenido en cuenta los siguientes criterios de codificación:

- Tipología de las fuentes. Clasificación realizada a partir de la adaptación de las propuestas de Borrat (2003) y Casero-Ripollés (2008) de las que se han extraído cinco categorías: fuente primaria, secundaria, anónima, oficial y profesional. En este artículo la variable de fuente profesional se ha utilizado para clasificar la intervención de entrevistados relacionados con el mundo del espectáculo como: músicos, actores, o estrellas del mundo de la televisión.

- Número de declaraciones únicas incluidas en cada noticia. Únicamente se ha contabilizado una intervención por entrevistado independientemente del número de cortes de voz que se han incluido de una misma persona en una pieza informativa. Se ha optado por cuantificar una única intervención por entrevistado para comprobar la incidencia real de participación ciudadana por noticia y su diversidad, es decir, se busca el número total de actores que aparecen en pantalla y no la cifra total de cortes de voz utilizados para documentar un hecho noticioso.

- Duración de cada una de las intervenciones. De esta manera se ha podido determinar el peso que tienen las diferentes fuentes que participan en los programas de infoentretenimiento.

Por lo que respecta al rol asignado a los periodistas en el modelo de análisis se han incluido diferentes variables para determinar el peso que recibe el redactor, tanto en la producción como en la posproducción de la pieza informativa, a partir de dos grandes bloques:

- Presencia del periodista en la noticia. En este apartado se ha tenido en cuenta la aparición o no en pantalla del redactor junto a los entrevistados, la locución de texto, la combinación de locución y aparición en pantalla, y la elaboración 
de entradillas a cámara. Asimismo, también se ha añadido una variable para determinar si el profesional de la información es el único protagonista de la pieza informativa.

- Interacción entre el presentador y el periodista en las conexiones en directo. Se han analizado las características comunicativas de este tipo de piezas informativas, en las que se ha prestado especial atención al diálogo que se establece entre el redactor y el presentador del programa. Se han incluido variables para determinar las diferentes técnicas utilizadas por cada espacio para mantener esas conversaciones en directo. Se ha valorado cómo se da paso y se despide el directo, si el diálogo se ha mantenido sin que el presentador aparezca en pantalla, o por el contrario, se ha utilizado el plasma o la técnica de la pantalla partida o la ventana pequeña para que ambos aparezcan en pantalla.

\section{Resultados. El papel de los ciudadanos en los programas de infoentreteni- miento}

\subsection{Las fuentes informativas en los programas de infoentretenimiento}

La mayor duración de las noticias de los programas de infoentretenimiento, puesto que oscilan entre los tres y los diez minutos, implica la necesidad de adoptar enfoques diferentes, dinámicos, que consigan mantener la atención de la audiencia. Estos formatos híbridos utilizan diferentes técnicas para lograrlo, entre ellas, aumentar la presencia de los protagonistas.

El ciudadano pasa a desempeñar un papel fundamental en la elaboración de estas nuevas noticias, puesto que el $97 \%$ de las entrevistas analizadas están protagonizadas por ciudadanos. Éstos han intervenido, principalmente, en calidad de fuente primaria (94\%), aunque también lo han hecho, en un porcentaje menor, como secundaria (2\%) o anónima (1\%) (Gráfico 1). Es un registro muy elevado que evidencia el peso que cobran los espectadores. Se busca el testimonio directo de los implicados, puesto que este tipo de programas están hechos por y para la audiencia.

En estos espacios híbridos las fuentes profesionales alcanzan una representación ínfima del 1\%. En la muestra analizada se han incluido tan solo un total de 8 declaraciones protagonizadas por cantantes, actores o personalidades relevantes relacionadas con el mundo del espectáculo. Por tanto, estas cifras revelan que en los programas de infoentretenimiento se descarta casi por completo la aplicación del criterio de noticiabilidad relativo a la notoriedad para realizar la selección informativa.

Las fuentes oficiales también quedan relegadas a un segundo plano ( $2 \%$ del total) (Gráfico 1). Tan sólo se recurre a su utilización para documentar aquellas noticias dedicadas a temáticas como los sucesos o la denuncia social, es decir, el tratamiento de este tipo de informaciones se asemeja más al que se utiliza en un programa informativo tradicional que trata de exponer todos los puntos de vista para ofrecer una noticia más completa, combinando los testimonios de las personas implicadas con la información aportada por las fuentes oficiales. En total han participado 44 voces institucionales divididas en: agentes de la Guardia Civil, Bomberos, Policía Local y Nacional y representantes políticos. En este tipo de programas la aparición de actores políticos es muy escasa. De hecho, participan únicamente representantes de corporaciones locales 
que no suelen tener cabida en los programas informativos tradicionales. Su aparición está ligada a la documentación de noticias vinculadas a las quejas y problemas cotidianos de los ciudadanos. Son alcaldes y concejales de pequeños municipios, remarcando la estrategia informativa de los programas de infoentretenimiento que apuestan por una información de proximidad, cercana al día a día de los ciudadanos.
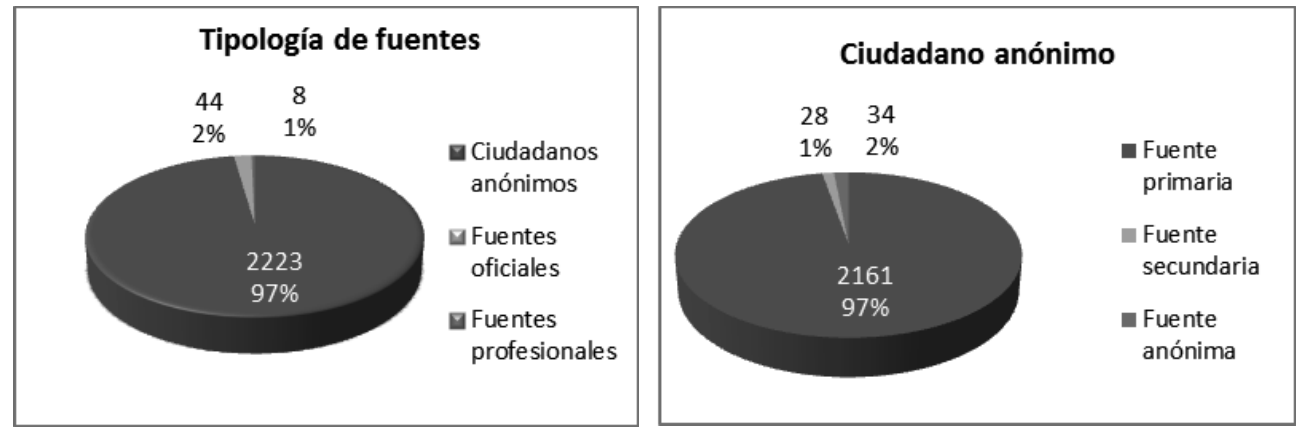

Gráfico 1. Relación de fuentes utilizadas (Fuente: elaboración propia)

Los resultados obtenidos revelan una tendencia homogénea a otorgar protagonismo indiscutible al ciudadano. El testimonio del espectador, convertido en fuente informativa de primer orden, se considera más relevante que el de las fuentes oficiales, incluso cuando ambas se presentan en una misma noticia. La única excepción la encontramos en aquellas noticias en las que solamente intervienen fuentes profesionales $(1 \%, 6$ noticias en total). En este caso se prescinde de la presencia del ciudadano porque prima la promoción de un producto por encima de la información, centrando la noticia en la presentación de un nuevo disco, película o programa televisivo. El único programa que no incluye este tipo de fuentes es España directo, una decisión justificada porque la aparición de este tipo de personajes se reservaba para el programa Gente, dedicado casi exclusivamente al tratamiento de la prensa rosa, que se emitía a continuación. Por el contrario, Andalucía directo es el programa que incluye más cortes de voz de fuentes profesionales ( 6 en total) representadas por 3 cantantes y 3 estrellas del mundo de la televisión (Tabla 1).

Estadísticamente, el espacio que incluye mayor variedad de testimonios es En Connexió (Canal 9), puesto que en las 113 noticias analizadas han participado 519 fuentes diferentes, una media de 4,57 testimonios por pieza emitida. Por el contrario, Andalucía directo (Canal Sur) es el programa que cuenta con una gama más reducida, ya que en las 205 noticias analizadas se han utilizado 433 cortes de voz diferentes, una media de 2,11 entrevistados por pieza informativa.

El ciudadano participa en la elaboración de la información mayoritariamente en calidad de fuente primaria. No obstante, en algunos casos se presentan como fuentes anónimas. Esto se justifica, por ejemplo, en aquellas temáticas relacionadas con sucesos o denuncia social, en las que los entrevistados prefieren ocultar su identidad. En connexió es el único programa de la muestra que no utiliza este tipo de fuentes, precisamente porque prescinde de este tipo de temáticas. Asimismo, tampoco utiliza fuentes secundarias, porque al igual que España directo, el programa de Canal 9 busca 
testimonios en primera persona. En definitiva podemos concluir que todos los programas de la muestra coinciden en otorgar el máximo protagonismo al ciudadano, independientemente de si éste participa como fuente primaria, secundaria o anónimamente.

Como se ha indicado anteriormente, la intervención de fuentes oficiales se limita a las noticias de sucesos o denuncia social. España directo es el programa que recurre con más frecuencia a este tipo de entrevistas, en total se han incluido 20 intervenciones de fuentes oficiales (un $2 \%$ del total) entre agentes de la Guardia Civil, Policía Local, Bomberos y representantes políticos. No obstante, si analizamos los porcentajes obtenidos, los datos revelan que Andalucía directo es el programa que utiliza más veces este tipo de intervenciones, puesto que a pesar de que sólo se incluyen 14 fuentes oficiales, su peso total respecto al resto de cortes de voz utilizados representan un $4 \%$, cifra que supera el porcentaje obtenido por España directo (Tabla 1). El programa de Canal 9, puesto que obvia este tipo de contenidos escabrosos, únicamente incluye los cortes de voz de dos bomberos en una noticia relacionada con los trabajos de rescate realizados después del terremoto de Haití.

Tabla 1. Relación del tipo de fuentes utilizadas por cada programa.

$\mathrm{N}=$ número total de fuentes consultadas (2.275). Fuente: elaboración propia

\begin{tabular}{|c|c|c|c|c|c|c|c|}
\hline \multirow[b]{2}{*}{ Programa } & \multicolumn{4}{|c|}{ Tipo de fuente: ciudadano anónimo } & \multirow[b]{2}{*}{$\begin{array}{c}\text { Tipo de fuente } \\
\text { profesional (artistas } \\
\text { y famosos) }\end{array}$} & \multirow[b]{2}{*}{$\begin{array}{l}\text { Tipo de } \\
\text { fuente: } \\
\text { fuente official }\end{array}$} & \multirow[b]{2}{*}{$\begin{array}{l}\text { Total fuentes } \\
\text { consultadas }\end{array}$} \\
\hline & Total & $\begin{array}{c}\text { Fuente } \\
\text { primaria }\end{array}$ & $\begin{array}{c}\text { Fuente } \\
\text { secundaria }\end{array}$ & $\begin{array}{c}\text { Fuente } \\
\text { anónima }\end{array}$ & & & \\
\hline $\begin{array}{l}\text { Madrid directo } \\
\text { (Telemadrid) }\end{array}$ & $486(98 \%)$ & $463(99 \%)$ & $20(4 \%)$ & $3(1 \%)$ & $1(1 \%)$ & $7(1 \%)$ & 494 \\
\hline $\begin{array}{l}\text { Andalucia directo } \\
\text { (Canal Sur) }\end{array}$ & $412(96 \%)$ & $385(90 \%)$ & $14(3 \%)$ & $14(3 \%)$ & $6(1 \%)$ & $14(4 \%)$ & 433 \\
\hline $\begin{array}{l}\text { España directo } \\
\text { (TVE) }\end{array}$ & $811(98 \%)$ & $798(98 \%)$ & 0 & $13(2 \%)$ & $0(0 \%)$ & $20(2 \%)$ & 831 \\
\hline $\begin{array}{l}\text { En connexió } \\
\text { (Canal 9) }\end{array}$ & $516(99 \%)$ & $516(99 \%)$ & 0 & 0 & $1(1 \%)$ & $2(1 \%)$ & 519 \\
\hline
\end{tabular}

\subsection{Características de las declaraciones de las fuentes informativas}

Las declaraciones realizadas por los ciudadanos comparten una serie de rasgos formales. La característica principal de este tipo de intervenciones es que su duración oscila entre los dos segundos y los siete segundos. Esto favorece la fragmentación y la aparición de un elevado número de fuentes por noticia, aportando dinamismo. Por esta razón, encontramos ejemplos como el de Madrid directo en el que en una pieza informativa emitida el 7 de junio de 2010 sobre un tema de denuncia social, en 1 minuto y 58 segundos se incluyeron las declaraciones de 15 ciudadanos diferentes, haciendo prevalecer los testimonios de los afectados por encima de la locución periodística. Las intervenciones no superaban en ningún caso los 5 segundos. El 9 de junio de 2010 En connexió incluyó una pieza sobre sociedad en la que en 3 minutos y 34 segundos participaron 19 fuentes diferentes, en este caso las intervenciones tampoco superaban los 5 segundos. Otro ejemplo lo encontramos en España directo, en un tema de sociedad en cuatro minutos y medio aparecieron 21 cortes diferentes, algunos de los entrevistados intervinieron más de una vez, pero en ningún caso superaron los 7 segundos. 
Por lo que concierne a las fuentes oficiales y a las profesionales, existen algunas diferencias respecto a las declaraciones de los ciudadanos anónimos. Independientemente de si se trata de agentes de los cuerpos de seguridad o de representantes políticos sus cortes de voz tienen una duración superior a aquellos realizados por el resto de fuentes. Si bien es cierto que adquieren una representación ínfima del 2\% en el balance final, sus intervenciones siempre superan los 7 segundos, llegando a incluirse cortes de 20 segundos. En el caso de que las piezas informativas incluyan fuentes profesionales, el peso de la noticia recae por completo sobre ellas, incluyendo declaraciones de hasta 30 segundos. Es decir, se recurre en pocas ocasiones al uso de este tipo de fuentes, pero su peso dentro de la noticia es mayor que el que se les otorga a los ciudadanos.

\section{Resultados. El papel del periodista en los programas de infoentretenimiento 7.1. La presencia del periodista en los programas del infoentretenimiento}

Una de las características más significativas de los formatos híbridos es el aumento del peso de la presencia de los periodistas en pantalla. El redactor aparece en plano en el 93\% de las noticias analizadas, es decir, en todos los vídeos, las conexiones en directo, los falsos directos y las pastillas (Gráfico 2). Tan sólo el 7\% de las noticias no lo incluyen en sus imágenes, que se corresponden con dos entrevistas telefónicas realizadas por Andalucía directo (Canal Sur) y 36 colas montadas a partir de material de agencia internacional, fragmentos de películas, de series o de programas de las diferentes cadenas a modo de autopromoción.

El aumento de protagonismo del periodista en pantalla facilita la aparición de un tipo de piezas informativas que prescinden de la tradicional locución de texto para dar forma a la noticia. El $45 \%$ de las piezas informativas emitidas en los programas analizados sustituyen la locución postproducida por fragmentos de entrevistas extraídas directamente del bruto y por entradillas a cámara realizadas por el redactor. La grabación de secuencias lineales completas permite crear clips de contenido con sentido propio que no precisan la introducción de texto en estudio para construir el relato. Se trata de una nueva tendencia que convive con el sistema clásico de hacer noticias (Cebrián Herrero, 1998; Díaz Arias, 2006; Olivia y Sitjà, 2007; Gordillo, 2009) en el que se intercala la voz locutada con los diferentes elementos de la noticia (cortes de voz, ambientes, entradilla a cámara). El 55\% de las piezas en formato vídeo analizadas siguen el sistema tradicional de redacción y montaje para elaborar noticias audiovisuales, es decir, combinan el texto locutado con las intervenciones de los periodistas y los entrevistados.

En los programas informativos tradicionales la presencia del periodista se limita a la realización de entradillas insertadas en los vídeos, a las conexiones en directo o a los falsos directos (Pestano Rodríguez, 2008). De esta manera, se traza una diferencia significativa respecto al papel que éstos desempeñan en los programas de infoentretenimiento. En estos espacios híbridos la presencia de los redactores es continua, puesto que aparecen en pantalla con los entrevistados. El uso de esta técnica conlleva una disminución de la inserción de entradillas a cámara del redactor en los vídeos, y en caso de incluirlas, no persiguen las mismas finalidades que los noticiarios clásicos. 
De las 378 noticias en formato vídeo analizadas, tan sólo en el 22\% de los casos se han incluido entradillas a cámara.

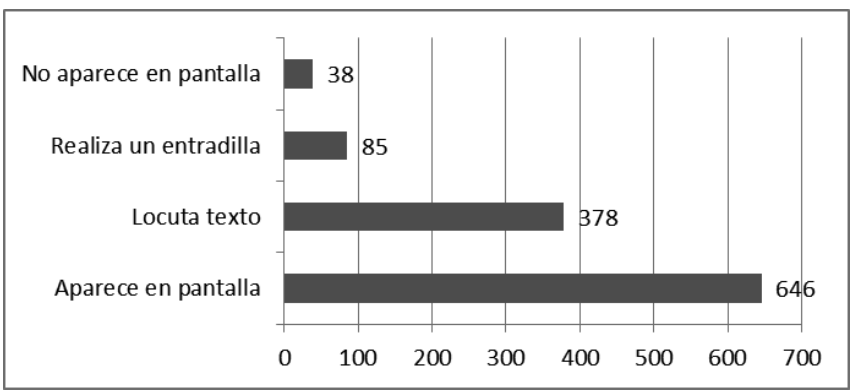

Gráfico 2. Presencia del periodista en los programas de infoentretenimiento. $\mathrm{N}=$ total de noticias analizadas (684). Fuente: elaboración propia

En una apuesta por la innovación, y posiblemente para diferenciarse de los programas informativos tradicionales, Madrid directo no utiliza las entradillas a cámara. En cambio, En connexió lo utiliza en el 57\% de sus vídeos. Por lo que respecta a España directo y a Andalucía directo el uso de esta técnica es más reducido buscando como única finalidad dar protagonismo a los periodistas (Tabla 2).

Tabla 2. Relación de uso de entradilla en la elaboración de vídeos por programa.

Fuente: elaboración propia

\begin{tabular}{|l|r|r|}
\hline \multicolumn{1}{|c|}{ Programa } & \multicolumn{1}{c|}{$\begin{array}{c}\text { Total } \\
\text { vídeos }\end{array}$} & \multicolumn{1}{c|}{$\begin{array}{c}\text { Vídeos con } \\
\text { entradilla }\end{array}$} \\
\hline $\begin{array}{l}\text { Madrid directo } \\
\text { (Telemadrid) }\end{array}$ & 80 & $0(0 \%)$ \\
\hline $\begin{array}{l}\text { Andalucia directo } \\
\text { (Canal Sur) }\end{array}$ & 89 & $22(25 \%)$ \\
\hline $\begin{array}{l}\text { España directo } \\
\text { (TVE) }\end{array}$ & 137 & $41(57 \%)$ \\
\hline $\begin{array}{l}\text { En connexió } \\
\text { (Canal 9) }\end{array}$ & 72 & $41 \%)$ \\
\hline
\end{tabular}

\subsection{El periodista como único protagonista de la noticia}

En los programas de infoentretenimiento los periodistas se convierten en una pieza casi imprescindible para elaborar y narrar, también en primera persona, lo que está sucediendo. En los espacios híbridos se refuerza la personalidad y el estilo de cada uno de los periodistas, y se apuesta por la identidad de las noticias. Su relevancia en el proceso de elaboración de la pieza informativa facilita que en ocasiones se convierta en el único participante de la noticia en el caso de algunas conexiones en directo. Al igual que sucede en los programas informativos tradicionales, el redactor es el único actor que aparece en pantalla. La diferencia reside en el hecho de que este tipo de directos superan los 3 minutos, lo que supone que el periodista deberá moverse, mostrar y narrar la información de forma atractiva para que el espectador no pierda el interés. El objetivo de estas noticias es que el periodista, aparte de aportar información, transmita 
la esencia de lo que está sucediendo en el lugar desde el que está realizando la conexión, a través de la imagen y de su intervención como testigo de los hechos.

Es el caso de los directos sobre meteorología, por ejemplo. Independientemente de si se realiza una previsión del tiempo a modo de información de servicio público, o en las ocasiones en las que los redactores muestran las consecuencias de un temporal, el periodista no comparte pantalla con ninguna fuente, convirtiéndose en redactorprotagonista que experimenta en primera persona y cuenta a la audiencia lo que está viendo-viviendo. En este tipo de piezas informativas se pone de manifiesto la importancia que adquiere el profesional que asume todo el peso de la noticia. Es capaz de realizar una intervención de 3 minutos a partir de información general, que combinará con aquella relacionada con la situación concreta del lugar desde el que se está informando a la audiencia.

Nos encontramos ante una nueva faceta del redactor ahora convertido en protagonista de la noticia. En este tipo de conexiones siempre se busca la imagen espectacular, como por ejemplo, meterse dentro de un río desbordado, o andar por la nieve para mostrar el grosor acumulado, todo para transmitir al espectador el dato curioso, la imagen insólita, aquello que no tendría cabida en un programa informativo tradicional y que se ha convertido ya en un signo distintivo para este tipo de espacios de infoentretenimiento.

\subsection{La relación entre el presentador y el periodista en las conexiones en directo}

Resulta evidente que el infoentretenimiento provoca una reasignación de las funciones que el periodista debe de asumir para elaborar una pieza informativa para estos nuevos programas. Su presencia se acentúa considerablemente, y su papel como coprotagonista o protagonista absoluto de la noticia cobra peso. Una tendencia que se refuerza además con la identificación de los profesionales de la información en la lectura de la entradilla de las piezas que se presentan en estos espacios híbridos. La finalidad que se persigue es que la audiencia se familiarice con los periodistas y reconozca el estilo personal de cada uno de los profesionales del programa.

Si en el apartado anterior describíamos al periodista como protagonista único, en este epígrafe se profundiza en una nueva vía que se usa para dar más juego al redactor: las conversaciones que se establecen entre el presentador y el periodista en las conexiones en directo. Este tipo de piezas informativas se han convertido en todo un símbolo para los programas de infoentretenimiento vespertinos que buscan la imprevisibilidad, la cercanía y la espontaneidad que sólo un directo puede ofrecer. El 36\% de las noticias analizadas se han presentado utilizando este formato de pieza informativa.

Los pasos a directo en los programas informativos tradicionales recrean un diálogo falsamente espontáneo entre el presentador y el periodista (Oliva y Sitjà, 2007). Cuando hablamos de diálogos en directo en los programas de infoentretenimiento, no nos referimos únicamente al que se establece al dar paso o despedir al redactor. Uno de los rasgos diferenciadores es que esas conversaciones pueden alargarse durante toda la noticia. En todas las conexiones en directo se entabla una conversación en tiempo real que permite a ambos profesionales interactuar de manera natural. En los 
directos de mayor duración el presentador puede realizar preguntas directamente a su compañero o al entrevistado para hacerlo más atractivo.

Para llevar a cabo esas conversaciones en directo se utilizan diferentes fórmulas, que pueden combinarse dentro de una misma conexión, para mantener la atención comunicativa. En primer lugar, el presentador puede interactuar sin aparecer en panta1la. Esta es la técnica más utilizada. En el $66 \%$ de los directos tan solo escuchamos la voz del conductor del programa mientras dialoga con su compañero (Tabla 3). Esta fórmula puede alternarse, además, con otras que sí que muestra en plano a los dos profesionales de la información, como puede ser la utilización de la pantalla de plasma ubicada en plató o de la pantalla partida. En ninguno de los programas se utiliza la técnica de la ventana pequeña.

Los cuatro programas analizados apuestan porque presentador y periodista mantengan conversaciones durante las conexiones en directo. La técnica más utilizada para llevar a cabo este diálogo pasa por ocultar al conductor del programa. No obstante, en aquellos casos en los que se opte por mostrar a los dos actores cada espacio sigue su propia técnica. Madrid directo apuesta por el uso del plasma mientras que $\mathrm{An}$ dalucía directo, España directo y En connexió se decantan, preferiblemente, por utilizar la técnica de la pantalla partida (Tabla 3).

Tabla 3. Relación de técnicas de diálogo por programa. $\mathrm{N} 1=$ Total directos (47), N2 = Total de directos (73), N3 = Total de directos (84), N4 = Total directos (39). Fuente: elaboración propia

\begin{tabular}{|l|r|r|r|r|r|}
\hline $\begin{array}{c}\text { Téenica de } \\
\text { diálogo }\end{array}$ & $\begin{array}{c}\text { Madrid directo } \\
\text { (Telemadrid) (N1) }\end{array}$ & $\begin{array}{c}\text { Andalucía directo } \\
\text { (Canal Sur) (N2) }\end{array}$ & $\begin{array}{c}\text { España } \\
\text { directo } \\
\text { (TVE) (N3) }\end{array}$ & $\begin{array}{c}\text { En Connexió } \\
\text { (Canal 9) } \\
\text { (N4) }\end{array}$ & TOTAL \\
\hline $\begin{array}{l}\text { No aparece } \\
\text { presentador en } \\
\text { pantalla }\end{array}$ & $36(77 \%)$ & $36(49 \%)$ & $60(71 \%)$ & $39(100 \%)$ & $\begin{array}{r}171 \\
(66 \%)\end{array}$ \\
\hline Plasma & $42(89 \%)$ & $1(1 \%)$ & $0(0 \%)$ & $0(0 \%)$ & $43(17 \%)$ \\
\hline Pantalla partida & $0(0 \%)$ & $6(8 \%)$ & $30(65 \%)$ & $7(5 \%)$ & $43(17 \%$ \\
\hline
\end{tabular}

\section{Conclusiones}

En base a los resultados obtenidos y retomando las hipótesis planteadas al inicio de este artículo podemos concluir que los ciudadanos anónimos se convierten en las fuentes informativas predominantes utilizadas en los programas de infoentretenimiento para elaborar las noticias.

El $97 \%$ de las fuentes consultadas por este tipo de programas de infoentretenimiento se corresponden con ciudadanos anónimos que han intervenido en calidad de fuente informativa prioritariamente primaria. Por tanto, podemos afirmar que los ciudadanos se convierten en la fuente de información predilecta, desplazando a los actores oficiales que tradicionalmente han abastecido a los programas informativos clásicos (López, 1995; Manning, 2001), puesto que en este tipo de espacios tan sólo alcanzan una representación del 2\%. Estos formatos híbridos otorgan un mayor peso al testimonio de los espectadores, convertidos en protagonistas de la información, apostando por un tipo de noticias más cercanas en las que lo cotidiano se convierte en hecho noticiable. Se demuestra, además, que este tipo de formatos huyen de los programas de sobremesa sobre noticias del corazón, puesto que la presencia de famosos se reduce al 1\%. Por tanto se obvia casi por completo la aplicación del criterio de no- 
toriedad para realizar la elección temática, constatando que el verdadero protagonista de la información es el ciudadano.

El nuevo papel que desempeña el ciudadano le confiere además un rol activo en el proceso de selección de la información llevada a cabo por los editores de los programas de infoentretenimiento. El espectador deja de ser un receptor pasivo para proponer sus propios temas al programa, incluso en ocasiones, ofrece su propio material audiovisual, y aproximadamente, en el 20\% de los casos (Ortells, 2012), esa iniciativa acabará transformándose en noticia. De esta manera, se dibuja un doble perfil en el papel de la audiencia. Por un lado, se convierte en el protagonista de las piezas informativas, y por otro, también pasa a formar parte del elenco de suministradores de noticias del que los periodistas pueden obtener nuevas informaciones, primicias, o incluso material audiovisual exclusivo.

Estos nuevos programas más cercanos y humanos apuestan por la identificación de la audiencia con los protagonistas de las noticias. Se convierten en ejemplos que reflejan los problemas y quehaceres cotidianos. La estrecha relación que se establece entre el periodista y el ciudadano también facilita que el espectador vea al redactor como un protagonista más que experimenta y vive lo mismo que ellos.

El análisis realizado permite verificar la segunda hipótesis que sostiene que el periodista pasa a convertirse en parte activa de la noticia en los programas de infoentretenimiento, asumiendo el rol de coprotagonista. El redactor aparece en pantalla junto con las fuentes en el $93 \%$ de las piezas, es decir, en los vídeos, las conexiones en directo, los falsos directos, e incluso en las pastillas. Las únicas piezas informativas que prescinden de la figura del periodista son las colas editadas únicamente a partir de imágenes extraídas de agencias, películas, series o videoclips.

Por tanto, podemos afirmar que en los programas de infoentretenimiento el periodista deja de ser un testigo neutral de los acontecimientos, que apenas aparece en pantalla y no muestra su opinión, como sucede en los programas informativos tradicionales, para convertirse en coprotagonista de sus propias noticias en las que aparece en plano prácticamente en todo momento, y se toma la licencia de tomar parte activa de los acontecimientos que le rodean. De hecho, en ocasiones el redactor se convierte en el único protagonista de la pieza informativa, basando su información en su propia experiencia, en lo que está viendo-viviendo. Se potencia además el diálogo en directo entre el redactor y el presentador del programa en el $100 \%$ de las conexiones en directo, apostando por la cercanía y la espontaneidad que caracterizan este tipo de programas.

En conclusión podemos afirmar que los papeles que desempeñan el ciudadano y el propio periodista en los programas de infoentretenimiento deben de considerarse como marcas identificativas de este tipo de formatos. El éxito cosechado por estos nuevos programas ha favorecido a que esos rasgos característicos influyan en las rutinas productivas de otros programas informativos convencionales que los incorporan progresivamente. Por tanto, el infoentretenimiento se erigen como fenómeno dotado de un potencial transformador del lenguaje informativo en televisión. 


\section{Referencias bibliográficas}

ALRIDGE, Meryl (2001): "Confessional culture, masculinity and emotional work" en Journalism, no 28, Vol. 1, pp. 91-98: http://jou.sagepub.com/content/2/1/91.short. [Consulta: 1 de marzo de 2011].

BAUM, Matthew (2002): "Sex, lies, and war: How soft news brings foreign policy to the inattentive public" en The American Political Science Review, no 96, pp. 91109: http://journals.cambridge.org/action/displayAbstract?fromPage=online \&aid=208460 [Consulta: 20 de febrero 2011].

BIRD, Elisabeth (2000): “Audience Demands in a Murderous Market, Tabloidization in U. S. Television News", en Sparks, Colin y Tulloch, John (eds): Tabloid Tales Global Debates over MediaStandarts. Oxford: Rovvman\& Littlefield.

BLUMER, Jay (1999): "Political communication system all change: a response to Kees Brants" en European Journal of Communication, $\mathrm{n}^{\circ}$ 14, vol. 2, pp. 241-249

BORRAT, Héctor (1989): El periódico como actor político. Barcelona, Gustavo Gili.

BRANTS, Kees (1998): “Who's afraid of infotainment?” en European Journal of Communication, $\mathrm{n}^{\circ}$ 13, Vol. 3, pp.: 315-335: http://ejc.sagepub.com/content/13/3/315.short [Consulta: 1 de septiembre de 2008]

BRANTS, Kees (2008): “Infotainment” en Kaid, L. L. y Holtz-Bacha, C. (eds.): Encyclopedia of Political Communication. Thousand Oaks, Sage.

CASERO-RIPOLLÉS, Andreu (2008): "La producción de la información audiovisual" en MARZAL, Javier y LÓPEZ CANTOS, Francisco Javier (eds.): Teoría y técnica de la producción audiovisual. Valencia, Tirant lo blanc.

CASERO-RIPOLLÉS, Andreu (2011): "Vida privada en la esfera pública: la intimidad de los actores políticos españoles en televisión", en CASERO-RIPOLLÉS, Andreu y MARZAL, Javier (eds.): Periodismo en televisión. Nuevos horizontes, nuevas tendencias. Zamora, Comunicación Social.

CEBRIÁN HERREROS, Mariano (1998): Información televisiva: mediaciones, contenidos, expresión, programación. Madrid, Síntesis.

CEBRIÁN HERREROS, Mariano (2003): Información televisiva. Mediaciones, contenidos, expresión y programación. Madrid, Síntesis.

CEBRIÁN HERREROS, Mariano (2004): La información en televisión. Obsesión mercantil y política. Barcelona, Gedisa.

CURRAH, Andrew (2009): What's Happened to Our News? Oxford, Challenges Series.

DADER, José Luís (2007): "Del periodista pasible, la obviedad informativa y otras confusiones en el Estanco de noticias" en Estudios sobre el mensaje periodístico, vol. 13, pp. 31-53. Madrid, Servicio de Publicaciones de la Universidad Complutense. 
DÍAZ ARIAS, Rafael (2006): Periodismo en televisión. Entre el espectáculo y el testimonio de la realidad. Barcelona, Ediciones Bosch, S. A.

DIMITROVA, Daniela \& STRÖMBÄCK, Jesper. (2009): "Look who's talking” en Journalism Practice, vol. 1, num. 3, pp. 75-91: http://www.tandfonline.com/doi/abs /10.1080/17512780802560773 [Fecha de consulta: 2 de febrero de 2011].

GANS, Herbert, J. (1979): Deciding what's news. A study of CBS Evening News, NBC Nightly News, Newsweek and Time. Nueva York, Pantheon Books.

GARCÍA AVILÉS, José Alberto (2011): "Dimensiones y tipología de las actividades de participación de la audiencia en la televisión pública" en Ámbitos, ${ }^{\circ}{ }^{20}$, pp. 175-195: http://grupo.us.es/grehcco/ambitos20/09garcia.pdf [Consulta: 3 de febrero de 2012].

GARCÍA DE TORRES, Elvira (2010): "Contenido generado por el usuario: aproximación al estado de la cuestión", en El profesional de la Información, vol. 6, n 19, pp. 585-593: http://elprofesionaldelainformacion.metapress.com/app/home/contribution.asp?referrer=parent\&backto=issue, 4,15 ;journal, 15,88; linkingpublicationresults,1:105302,1 [Consulta: 12 de enero de 2013].

GORDILLO, Inmaculada (2009): Manual de narrativa televisiva. Madrid, Síntesis.

HARRINGTON, Stephen (2008): "Popular news in the 21 century: Time for a new critical approach?" en Journalism, vol. 3, núm. 9, pp. 266-284: http://jou.sagepub.com/content/9/3/266.short [Fecha de consulta: 15 de mayo de 2011].

KRÜGER, Udo Michael (1988): “Infos- Infotainment- Entertainment?” en Media Perspektiven, num. 10, pp. 537-664.

LÓPEZ, Manuel (1995): Cómo se fabrican las noticias. Fuentes, selección y planificación. Barcelona, Paidós.

LOZANO, José Carlos (2005): “Tendencias hacia la espectacularización y el sensacionalismo en la información política televisiva: un estudio comparativo de noticieros mexicanos, canadienses y estadounidenses", en LOZANO, J. C. (Ed.): La comunicación en México: Diagnósticos, balances y retos. México, CONEICC e ITESM.

MCMANUS, John (2009): "The commercialization of News", in WAHL-JORGENSEN, Karin y HANITZSCH, Thomas: The handbook of journalism studies. New York and London, Routledge.

MANNING, Paul (2001): News and News sources: a critical introduction. London, Sage.

MISSIKA, Jean Louis. (2006): La fin de la télévision. Paris, Éditions du Seuil et La République des Idées.

MONCLUS, Belén y VICENE-MORIÑO, Miguel (2010): “The influence of Infotainment in the Role of TV Newscasts' Main Characterts" en Observatorio (OBS*) Journal, $\mathrm{n}^{\mathrm{o}}$ 4, vol. 2, pp. 67-90: http://obs.obercom.pt/index.php/obs/article /viewArticle/340 [Consulta: 16 de octubre de 2012]. 
NGUYEN, An (2012): "The effect of soft news on public attachment to the News" en Journalism Studies, $\mathrm{n}^{\mathrm{o}}$ 13, Vol. 5, pp. 1-12: DOI: 10.1080/1461670X.2012.664318 [Fecha de consulta 1 de febrero de 2013].

OLIVA, Llúcia y SITJÀ, Xavier (2007): Las noticias en radio y televisión. Periodismo audiovisual en el siglo XXI. Barcelona, Omega.

ORTELLS-BADENES, Sara (2009): "La mercantilización de la información: la nueva era informativa en televisión", en RLCS, Revista Latina de Comunicación Social, núm. 64, pp. 341-353: http://www.revistalatinacs.org/09/art/28_827_46_ULEPICC_07/Sara_Ortells.html

ORTELLS-BADENES, Sara (2012): "Información televisiva y redes sociales: nuevas vías para la distribución de contenidos audiovisuales", en LEÓN, Bienvenido (coord.): La televisión ante el desafio de Internet. Salamanca, Comunicación Social.

PAULUSSEN, Steve \& D'HEER, Evelien (2013): “Using Citizens for Community Journalism. Findings from a hyperlocal media project". Journalism Practice: DOI:10.1080/17512786.2012.756667 [Consulta: 1 de febrero de 2013].

PESTANO RODRÍGUEZ, José (2008): "Estado y tendencias de la información audiovisual: la presencia del periodista en los informativos de televisión", en Estudios sobre el Mensaje Periodístico, vol. 14, pp. 543-560. Madrid, Servicio de Publicaciones de la Universidad Complutense: http://revistas.ucm.es/index.php /ESMP/article/view/ESMP0808110543A/11998 [Consulta: 3 de marzo de 2011].

PRADO, Emili et al. (1999): "El fenónemo Infoshow: la realidad está ahí fuera", en Área 5, Revista de Comunicación Audiovisual y Publicitaria, vol. 6, pp. 197-210.

PRIOR, Markus (2003): "Any good News is soft News? The impact of soft News preference on political knowledge". Political Communication, vol 20, pp. 149171. DOI: 10.1080/10584600390211172 [Consulta: 21 de marzo de 2009].

REINEMANN, Carsten et al. (2012): "Hard and soft news: a review of concepts, operationalizations and key findings". Journalism, vol. 2, num. 13, pp. 221-223: http://jou.sagepub.com/content/13/2/221.short [Consulta: 28 de noviembre de 2012].

ROWE, David (2010): “Tabloidization of news", en ALLAN, Stuart (ed.): The Routledge companion to news and journalism. Oxon, UK, Routledge.

SPARKS, Colin (2000): "Introduction: the panic over tabloid news", in SPARKS, Colin \& TULLOCH, John (ed.): Tabloid tales: Global perspective on the popular media. Maryland, Rowman and Littlefield, Inc.

THOMAS, Bill (1990): Finding Truth in the Age of «Infotainment». Washington D.C., Research Reports.

THUSSU, Daya Kissan (2007): News as entertainment. London, Sage. 
TURNER, Graeme (2006): “The mass production of celebrity: 'celetoids' reality TV and the 'demotic turn'". International Journal of Cultural Studies, Vol. 2, n' 9 , pp. 153-165. DOI: 10.1177/1367877906064028 [Consulta: 3 de junio de 2009].

VAN ZOONEN, Liesbet (1998): A Tyranny of Intimacy? Women, Femininity and Television News. London, Sage. 